\title{
A systematic review of the safety of non-tumour necrosis factor inhibitor and targeted synthetic drugs in rheumatic disease in pregnancy
}

\author{
Authors: Kawser Ahmed, ${ }^{A}$ Ian Giles, ${ }^{B}$ Hanh Nguyen ${ }^{B}$ and Julia Flint ${ }^{C}$
}

\begin{tabular}{|c|c|c|c|c|c|c|c|}
\hline Drug & Studies & $\begin{array}{l}\text { Pregnancy } \\
\text { exposures }\end{array}$ & Live births & $\begin{array}{l}\text { Spontaneous } \\
\text { miscarriages }\end{array}$ & $\begin{array}{l}\text { Congenital } \\
\text { malformations }\end{array}$ & $\begin{array}{l}\text { Breastfeeding } \\
\text { exposures }\end{array}$ & $\begin{array}{l}\text { Adverse effect } \\
\text { of drug }\end{array}$ \\
\hline Abatacept & $3 \mathrm{ct}, 1 \mathrm{cs}$ & 151 & 87 & 40 & 4 & ns & No \\
\hline Anakinra & $4 \mathrm{cs}, 2 \mathrm{cr}, 2 \mathrm{ct}$ & 46 & 43 & ns & 1 & 13 & No \\
\hline Belimumab & $4 c r, 2 r v$ & 250 & 104 & 58 & 12 & ns & No \\
\hline Canakinumab & $1 \mathrm{cr}, 1 \mathrm{ct}$ & 9 & 8 & 1 & ns & 4 & No \\
\hline Ixekizumab & $1 \mathrm{ct}$ & 3 & ns & ns & ns & ns & ns \\
\hline Rituximab & $22 \mathrm{cr}, 9 \mathrm{cs}, 4 \mathrm{ct}$ & 198 & 131 & 36 & 3 & 2 & No \\
\hline Secukinumab & $1 \mathrm{cr}$ & 1 & 0 & 1 & ns & ns & ns \\
\hline Tocilizumab & $2 \mathrm{cs}, 4 \mathrm{ct}$ & 361 & 220 & 82 & 59 & 4 & No \\
\hline Tofacitinib & $1 \mathrm{cs}$ & 41 & 26 & 7 & 1 & 0 & No \\
\hline Ustekinumab & $7 \mathrm{cr}, 7 \mathrm{cs}, 2 \mathrm{ct}$ & 29 & 26 & 4 & 0 & ns & No \\
\hline
\end{tabular}

\section{Background}

Despite increasing evidence to support safe use of tumour necrosis factor inhibitor (TNFi) drugs in pregnancy, there remains a paucity of evidence regarding non-TNFi and targeted synthetic disease-modifying anti-rheumatic drugs (tsDMARDs) in pregnancy. Therefore, we conducted a systematic review to summarise use of these drugs in pregnancy and breastfeeding.

\section{Method}

We performed a systematic search of databases including EMBASE, PubMed (MEDLINE) and Cochrane up to December 2018, using keywords including commonly prescribed nonTNFi and tsDMARDs, pregnancy, conception/pre-conception, lactation/breastfeeding, childhood and vaccination/infection.

Authors: ${ }^{A}$ UCL Medical School, London, UK; ${ }^{B}$ University College London Hospitals NHS Foundation Trust, London, UK; ' Queen Elizabeth Hospital, Birmingham, UK

\section{Results}

From an initial screen of 700 papers, 92 full-text papers were included in the final analysis. A summary of findings from known outcomes of pregnancy and breastfeeding exposures, as well as long-term follow-up of infants where available, is shown in Table 1. Overall, these data do not identify an increased risk of adverse pregnancy outcomes with these drugs in this population of patients.

\section{Conclusion}

These findings do not suggest an increased risk of non-TNFi and tsDMARDs in pregnancy. However, given that the total number of exposures remains limited, these drugs should only be considered in pregnancy if the benefit of maintaining disease control in the mother justifies any potential risk to the fetus. This body of evidence will be useful when counselling women about the potential risks of using these types of drugs during pregnancy and the breastfeeding period, as well as following accidental exposure to drugs at conception.

\section{Conflicts of interest}

None declared. 